\title{
Redescription of Ceriagrion mourae with notes on its position in the genus Ceriagrion (Odonata: Coenagrionidae)
}

\author{
Rafał Bernard $^{\mathrm{a} *}$, Bogusław Daraż ${ }^{\mathrm{b}}$ and Miroslawa Dabert ${ }^{\mathrm{c}}$ \\ ${ }^{a}$ Department of Nature Education and Conservation, Faculty of Biology, Adam Mickiewicz University in \\ Poznań, Poland ${ }^{b}$ Kościelna 41, Rzeszów, Poland ${ }^{c}$ Molecular Biology Techniques Laboratory, Faculty of \\ Biology, Adam Mickiewicz University in Poznań, Poland
}

(Received 16 October 2017; accepted 10 April 2018)

\begin{abstract}
The poorly known Ceriagrion mourae is redescribed based on the first material from Zambia and compared with the similar $C$. banditum, $C$. junceum and $C$. suave. Molecular data place $C$. mourae as a sister taxon to the clade (C. bakeri (C. banditum, C. junceum)). Genetic distances between the above-mentioned species are similar at $c .7-9 \%(\mathrm{~K} 2 \mathrm{P})$. Analysis of all published Ceriagrion COI sequences revealed a barcoding gap (c.2-6.5\%) in the pairwise distance distribution and grouped African sequences according to the known species, except $C$. suave and $C$. glabrum. C. mourae was only found at a pool on a temporary stream, which differed from others in the study area by its combination of vegetation and shading. The Zambian locality and two earlier known sites in Mozambique and Tanzania are scattered across the plains and low hills of eastern and southern central Africa.
\end{abstract}

Keywords: damselfly; Zygoptera; Africa; Zambia; species diagnosis; taxonomy; COI; DNA barcoding

\section{Introduction}

Africa still amazes us: 60 new species of dragonflies and damselflies were described in one paper recently, showing our poor knowledge of Afrotropical biodiversity, even in such a spectacular and easy to study group as Odonata (Dijkstra, Kipping, \& Mézière, 2015). The authors described three new species of Ceriagrion, of which $C$. banditum Kipping \& Dijkstra and C. junceum Dijkstra \& Kipping occur in southern central Africa, in the zoogeographical region of Zambezia. This region is one of the main diversity centres of Odonata in the Afrotropics and the diversity centre of Ceriagrion in Africa (Dijkstra et al., 2011, 2015). This status was strengthened by our discovery of a further species, C. mourae Pinhey, 1969, in central Zambia. It was previously known only from two distant localities in East Africa, the type locality Mamunge in Mozambique (Pinhey, 1969) and the southern slopes of the Kichi Hills in the Rufiji District in eastern Tanzania (Clausnitzer, 2006), where one male and two teneral males were collected respectively. Individuals from Zambia have shown that the original description (Pinhey, 1969) is insufficient and unrepresentative for the species as far as coloration and markings are concerned. The holotype in the Natural History Museum of Zimbabwe in Bulawayo is discoloured (Figure 1) and the Tanzanian individuals were teneral, which means that our Zambian material is the first to

*Corresponding author. Email: rbernard@ amu.edu.pl 


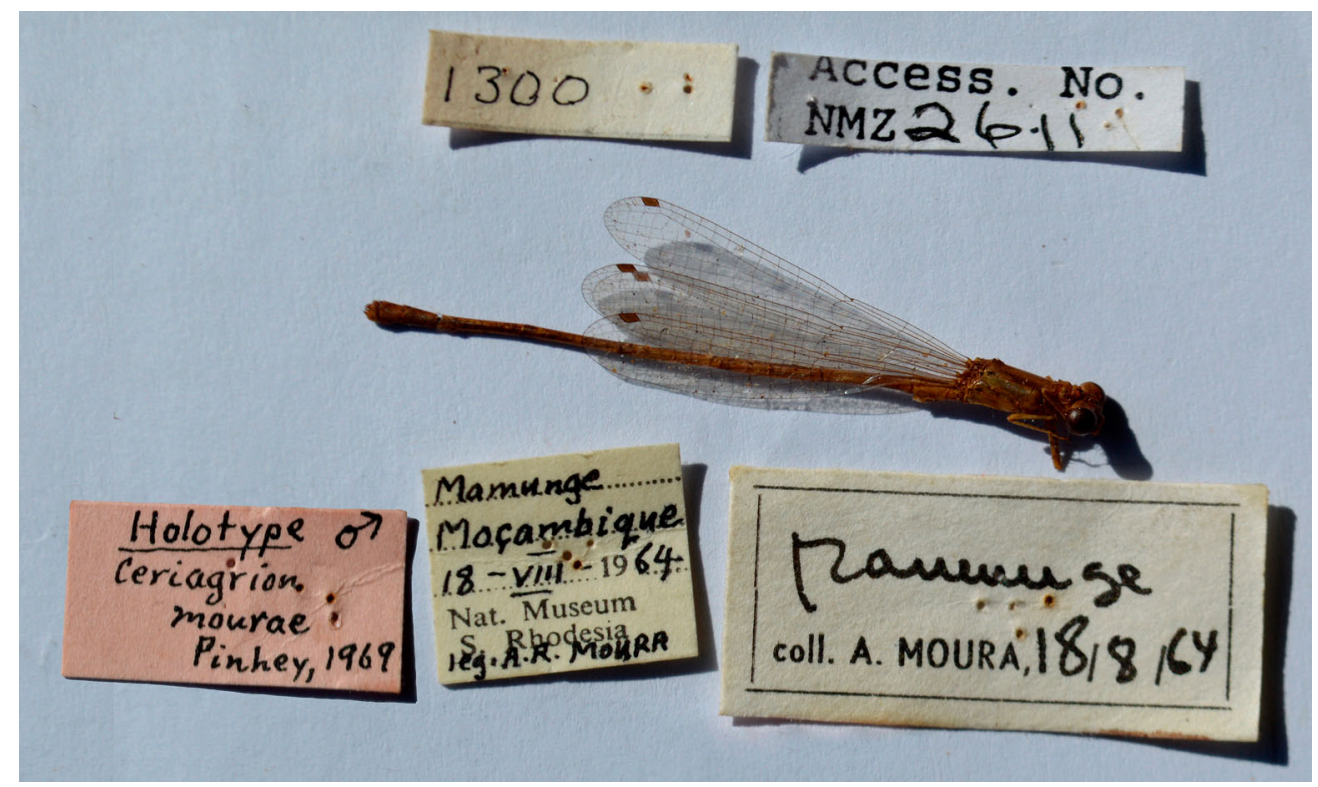

Figure 1. Holotype of Ceriagrion mourae Pinhey, 1969 (the Natural History Museum of Zimbabwe in Bulawayo). Photo Kudzai Mafuwe.

present the species' colours in life. We (a) redescribe $C$. mourae and diagnose it relative to its most similar congeners, (b) discuss the species' phylogenetic position, and (c) provide the first biological and ecological data.

\section{Materials and methods}

\section{Locality}

A small pool on the Mulembwe (= Milembwe) temporary stream, $14.40759^{\circ} \mathrm{S}, 29.98443^{\circ} \mathrm{E}$, $528 \mathrm{~m}$ asl, the Luano Valley, i.e. the rift valley drained by the Lukusashi River system, $2.36 \mathrm{~km}$ $\mathrm{NE}$ of the Chingombe catholic mission, Luano District, Central Province, Zambia.

\section{Individuals examined}

Ten individuals of $C$. mourae were collected by R. Bernard and B. Daraż: eight males (four mature and four teneral) and two females (mature and teneral). 20 April 2015-1 teneral male; 21 April 2015-1 teneral male; 23 April 2015-2 males, 1 female, all teneral (the female confirmed genetically); 16 January 2017-3 mature males; 17 January 2017-1 male and 1 female in a tandem.

All the individuals are in the collection of Rafał Bernard in the Nature Collections of the Faculty of Biology, Adam Mickiewicz University in Poznań, Poland.

\section{Morphological analysis}

Measurements were made only for mature individuals. Dimensions are given in millimetres; the range and, if reasonable, mean \pm SD are included. Abdominal length excludes appendages. 
The following abbreviations are used: $\mathrm{Fw}=$ forewing; $\mathrm{Hw}=$ hindwing; $\mathrm{Pt}=$ pterostigma; $\mathrm{S} 1-$ $10=$ abdominal segments 1 to $10 ; \mathrm{Px}=$ postnodal cross-veins. For diagnostic comparisons, specimens of $C$. banditum, $C$. junceum and $C$. suave Ris (from our and J. Kipping's collections) and published data (Dijkstra et al., 2015) have been used.

\section{Molecular analysis}

Genomic DNA was extracted from legs using the Qiagen DNeasy Blood \& Tissue Kit (Qiagen, Hilden, Germany). A DNA-barcode fragment of the mitochondrial cytochrome $c$ oxidase subunit I (COI) gene was amplified with primers bcdF01 (CATTTTCHACTAAYCATAARGATATTGG) and bcdR04 (TATAAACYTCDGGATGNCCAAAAAA) (Dabert, Witalinski, Kazmierski, Olszanowski, \& Dabert, 2010). PCR was performed in a total reaction volume of $10 \mu \mathrm{l}$ containing HOT FIREPol Blend Master Mix (Solis Biodyne, Tartu, Estonia), $0.5 \mu \mathrm{M}$ each primer, and $4 \mu \mathrm{l}$ of DNA template using a thermocycling profile of one cycle of $12 \mathrm{~min}$ at $95^{\circ} \mathrm{C}$ followed by 35 steps of $15 \mathrm{~s}$ at $95^{\circ} \mathrm{C}, 1 \mathrm{~min}$ at $50^{\circ} \mathrm{C}$, and $1 \mathrm{~min}$ at $72^{\circ} \mathrm{C}$, with a final elongation step of $5 \mathrm{~min}$ at $72^{\circ} \mathrm{C}$. PCR products were purified with thermosensitive exonuclease I and FastAP alkaline phosphatase (Fermentas, Thermo Scientific, Waltham, MA, USA) and sequenced with BigDye Terminator v3.1 on an ABI Prism 3130XL Analyzer (Applied Biosystems, Foster City, CA, USA). Sequence chromatograms were checked for accuracy using FinchTV 1.3.1 (Geospiza Inc., Seattle, WA, USA) and contigs were assembled in Geneious R10 (Biomatters Ltd, Auckland, New Zealand). Sequences were published in GenBank under accession numbers MF947157-62 (C. mourae) and MF974576 (C. suave).

\section{Sequence and phylogenetic analyses}

For comparison of COI data we used the published sequences for Ceriagrion (106), sequences of C. mourae found in this study (6), one sequence of $C$. suave found in this study and a sequence of Austrocoenagrion lyelli used as an outgroup (for details see Supplemental Table S1). Sequences were aligned using MUSCLE as implemented in Geneious 10. Phylogenetic analyses for species delimitation were carried out with the neighbour-joining (NJ) method as implemented in MEGA7 (Kumar, Stecher, \& Tamura, 2016). Pairwise distance calculations between nucleotide sequences were computed using Kimura's 2-parameter (K2P) distance model (Kimura, 1980) for all codon positions using MEGA7. The COI sequence data were analysed using the Automatic Barcode Gap Discovery (ABGD) method to delimit genetic clusters by detecting a significant gap in the pairwise distance distribution (Puillandre, Lambert, Brouillet, \& Achaz, 2012). We used the online ABGD version (http://wwwabi.snv.jussieu.fr/public/abgd/abgdweb.html) with default settings and K2P distance model.

The best fit model of DNA evolution chosen by PartitionFinder2 (Lanfear, Calcott, Ho, \& Guindon, 2012) was TIM $+\mathrm{I}+\mathrm{G}, \mathrm{F} 81+\mathrm{I}$, and $\mathrm{K} 81 \mathrm{uf}+\mathrm{G}$ for the first, second, and third codon position, respectively. Phylogenetic trees were reconstructed using maximum likelihood (ML) in Garli v.2.0 (Zwickl, 2006) and Bayesian inference (BI) in MrBayes 3.2 (Ronquist et al., 2012). Each run of four independent chains was performed in $10 \times 10^{6}$ generations, and the trees were sampled every 1000 generations. The final consensus tree was generated after discarding the burn-in fraction of $25 \%$ initial trees where the average standard deviation of split frequencies dropped $<0.003$. Support for nodes in BI analysis was estimated from posterior probabilities (PP) of each bipartition calculated for remaining trees representing the percentage of times each node was recovered by $50 \%$ majority rule consensus. 


\section{Results}

\section{Species redescription of Ceriagrion mourae Pinhey, 1969}

Male (Figures 2a-e, 3)

Head Dorsal parts cryptic, brown: darker and matt-velvety between the vertex and eye margins, lighter and warmer in occiput, occipital lobes and near frons, and ochreous-brown in postfrons and postclypeus. Frontal parts bright: labrum intensively warm yellow and antefrons, anteclypeus, mandible bases and genae yellow with olive greenish and brownish shades. Labium pale yellow laterally to off-white centrally, partly almost hyaline. Eyes divided into the olive green upper part and the citron yellow lower part. Two distinct rings like a bandit mask (further called 'bandit' rings) in the upper half: well visible alive and in specimens in alcohol, but hardly, if at all, in dry specimens after acetone dehydration.

Prothorax Dorsally ochreous with brownish and golden tones. Yellowish buff laterally and off-white with wax pruinescence on the ventral side.

Synthorax Generally ochreous, paler ventrally. Mesepisternum - ochreous with golden and orange tones, mesepimeron similar, lighter. Metepisternum yellowish-ochreous and metepimeron paler. On the ventral side off-white with yellowish or greyish tinge and white wax pruinescence. A (pale) blackish chevron-like spot on poststernum. Sutures. Humeral and metapleural sutures with a thin brown line: dark in the former and pale in the latter. Fossae. Strongly contrasting, very dark brown to black in the both humeral and metapleural sutures. Antealar ridge. Brown.

Legs Off-white to ochreous. Coxae off-white to pale buff, with white vax pruinescence. Tibiae and femora buff-ochreous, tibiae more uniform and femora more contrasted: pale ventrally and with a dark brown to blackish stripe along dorsum. Spines black. Claws reddish amber with the apex and both hooks black.

Wings Hyaline. Venation brown, with paler veins in the proximal half of the wing and postnodal costa. Pterostigma. A dark brown oblique parallelogram, in some cases slightly broadened distally. Px number. For eight individuals: in Fw 10-12 (mostly 11), and in Hw 9-10.

Abdomen Generally dull orange. On closer inspection, most segments orange, with a red tone dorsally and yellowish-ochreous on the ventral side. S1 orange dorsally and yellowish-ochreous laterally. S10 mostly reddish brown. Narrow darkened (brownish) rings at the distal end of S3, S4, S5 and S6, well visible in the ventral up to laterodorsal view. An invaginated dorsal distal edge of S10 minutely notched dark brown to blackish.

Cerci Brownish with a partly blackish inner margin. In dorsal view (Figure 3a) fairly broad and oval. The inner margin angled, forming a weak tooth slightly proximally to the midlength. Magnified cercus appears structured into a broader outer part and a narrower depressed inner 'ledge'.

Paraprocts Paler than cerci, brownish-ochreous with a black distal tooth. Their tips slightly exceeding beyond tips of cerci, in tenerals this may be even invisible. In lateral view (Figure $3 \mathrm{~b})$, the lower margin angular $\left(c .130^{\circ}\right)$ with an obtuse 'heel' and the strong terminal branch directed dorsodistally. The upper margin horizontal, at most with a small knob near the base, and terminated by a black tooth. 

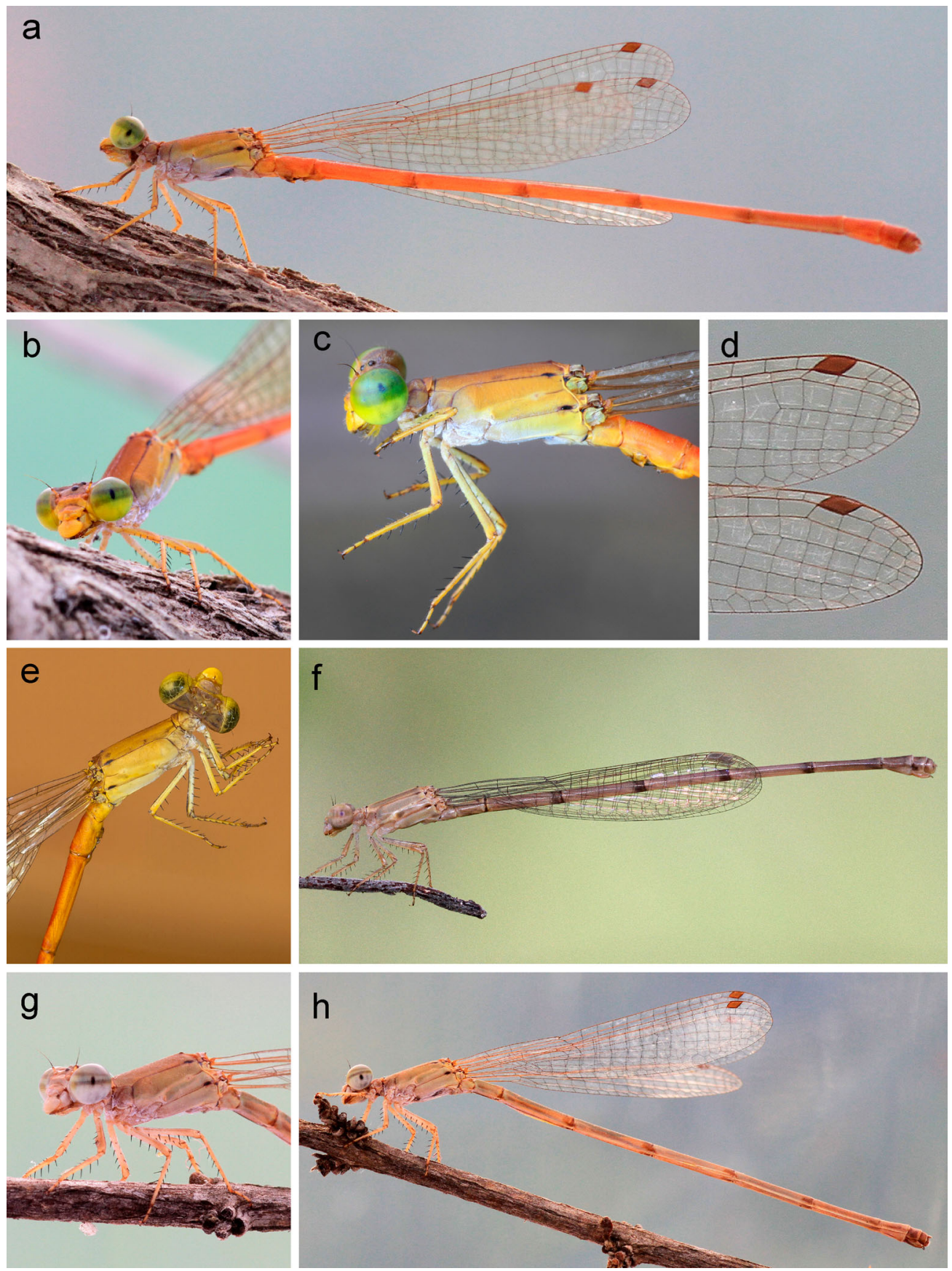

Figure 2. Ceriagrion mourae from Chingombe, Zambia, (a-e) male; (f-h) female: (a) ventrolateral, slightly overexposed view, visible abdominal rings on S3-6; (b) laterofrontal view, visible 'bandit' eye rings, yellow frontal signal and three colouristically different main parts of the body; (c) head and thorax in lateral view, visible gradually merging ochreous to off-white colours of synthorax and black fossae; (d) pterostigma on fore- and hindwings; (e) specimen in collection with fairly well-preserved colours; (f) teneral with distinct abdominal rings on S3-6; (g) mature in frontolateral view, visible 'bandit' rings on eyes and blackish fossae; (h) mature in ventrolateral, slightly overexposed view. 
a

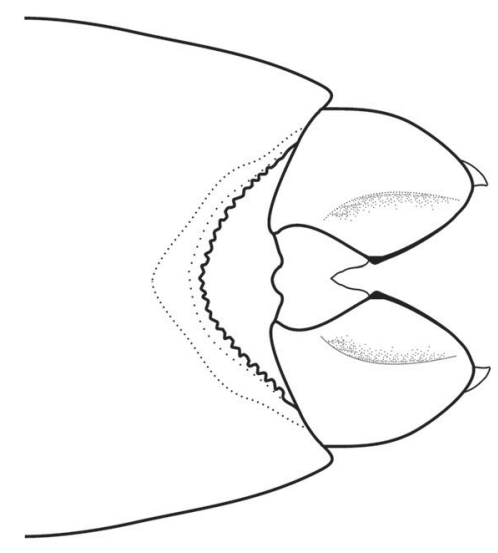

b

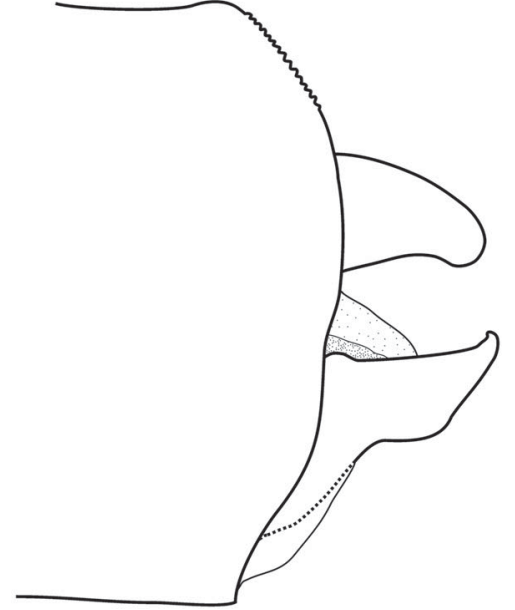

Figure 3. Anal appendages of Ceriagrion mourae: (a) dorsal view; (b) lateral view.

Genital ligula Close to Ceriagrion bakeri Fraser, 1941 (see fig. 20 in Dijkstra \& Clausnitzer, 2014), with finger-like lateral lobes and a small depression between them and a distal part.

Dimensions The species of medium size, but one of the greatest Ceriagrion in southern central Africa. Four males: total length 40.3-43.2 (41.7 \pm 1.16 ); abdominal length 32.5-35.0 $(33.7 \pm 0.98)$; Hw 20.2-21.6 (20.9 \pm 0.65$)$; Pt $0.8 \mathrm{~mm}$; ratio Hw/total length $49.8-50.8 \%$ $(50.2 \pm 0.40 \%)$. Wings' range: $c .1 / 3$ of the S6 length.

\section{Diagnosis}

C. mourae is distinct within the most similar species especially by shape of its cerci in dorsal view and abdominal pattern of darkened rings on S3-6.

Several other traits, shared with or similar to some related species (cf. Dijkstra et al., 2015), are also typical of mourae, i.e.: (a) moderate size, Hw 20.2-21.6, slightly smaller than C. banditum; (b) sleek build, with wing tips reaching a third down the length of S6 and ratio Hw/total length 49.8-50.8\% (like C. banditum); (c) two 'bandit' rings on eyes (like C. banditum); (d) black dots in fossae of humeral and metapleural sutures (as in $C$. junceum, but larger and darker, more contrasting); (e) dark brown pterostigma (darker than in C. junceum, C. suave and a coexisting form of C. glabrum); (f) contrasting, dark brown to blackish dorsal stripe on each femur (slightly darker than in C. junceum), (g) clear colouristic division of the body into brown-yellowgreen head, ochreous thorax and dull orange abdomen; (h) genital ligula with finger-like lateral lobes (like C. bakeri, $C$. banditum and C. junceum); (i) dorsal distal edge of S10 dark and minutely notched (like $C$. banditum and $C$. junceum); and (j) paraprocts with tips slightly exceeding beyond tips of cerci, and with a lower margin weakly angular and the distal part directed diagonally - dorsodistally (similar to C. junceum, but slightly longer and sleeker).

For the most similar relatives there are several traits differing from C. mourae. Apart from shape of cerci in dorsal view and lacking abdominal pattern of darkened rings on S3-6, this differing combination includes:

- for C. banditum: (a) dots in fossae pale brownish and thus weakly contrasting; (b) pterostigma pale, often reddish; (c) paraprocts with a lower margin strongly angled, with an evident 'heel', 
and directed dorsally with tips falling clearly short of those of the cerci; (d) stripe on the dorsum of each femur absent;

- for C. junceum: (a) smaller, Hw 18.5-20.5; (b) eyes more uniformly green from lighter underside to darker top; (c) 'bandit' rings on eyes absent; (d) a small dark spot as a cap on the eye top (in mourae absent); (e) labrum paler than in mourae, creamy yellow; (f) dorsal and lateral parts of synthorax more contrasting than in mourae, as a result synthorax two-toned; $(\mathrm{g})$ pterostigma pale (greyish) brown;

- for C. suave: (a) less sleek, with wing tips reaching halfway down S6 and ratio Hw/total length 51-57\%; (b) 'bandit' rings on eyes absent; (c) dots in fossae absent or barely recognizable along the suture, brownish; (d) pterostigma pale brown; (e) wings largely yellow-stained; (f) genital ligula without finger-like lobes; (g) dorsal distal edge of S10 pale, unnotched; (h) paraprocts with lower margin strongly angled, with an evident 'heel', and directed dorsally with tips reaching distally as far as those of cerci; (i) dorsal stripe on femur absent or short and diffused, pale brown.

\section{Female (Figure $2 f-h$ )}

Head Dorsal parts brown: richer in occiput and occipital lobes, matt-velvety between the vertex and eye margins, and paler with olive tones near frons. Eyes olive grey, lighter in the lower half and darker with greenish hint and with two 'bandit' rings in the upper half (dark green after acetone dehydration). Frons, clypeus, mandible bases and genae pale, olive-greyish with ochreous or yellowish tones locally. Labrum yellowish buff. Labium creamy, centrally almost hyaline.

Prothorax Yellowish ochreous dorsally, pale yellowish with olive shade laterally.

Synthorax Generally ochreous, with golden tones on mesepisternum and paler laterally, down to yellowish buff on metepimeron. Diffuse olive spots or at least olive hint on each part. On the ventral side pale with buff and greyish tones, and with wax pruinescence. Dark brown spots on poststernum: a small one anteriorly and diffuse chevron-like centrally. A pair of transverse narrow and slightly arched depressions at the proximal edge of the mesepisternum. Sutures. Humeral and metapleural sutures with a thin brown line, pale in the latter. Fossae. Strongly contrasting, very dark brown to black in the both humeral and metapleural sutures. Antealar ridge. Brown.

Legs Coxae off-white to pale buff with vax pruinescence. Femora off-white ventrally and pale ochreous dorsally, with a dark brown to blackish stripe along dorsum. Tibiae ochreous-buff. Spines black. Claws reddish amber with the apex and both hooks black.

Wings Hyaline. Venation brown, with paler veins in the proximal half of the wing and postnodal costa and R2. Pterostigma. Dark brown oblique parallelogram, in Hw slightly broadened distally. Px number. For two females: in Fw 12, Hw 10.

Abdomen Mottled, pale with diffuse dark shades. S1-6 ochreous-buff, S3-6 with large dorsal greyish-olive spots. S7-S10 warm brown with ochreous admixtures. Brownish rings at the distal end of S4, S5, S6 and weaker on S3. On the ventral side pale with buff tones. Cerci. Brown.

Dimensions One female: total length 43.7; abdominal length 35.0; Hw 22.4; Pt 0.8 mm; ratio Hw/total length $51.3 \%$. Wings' range: $c .2 / 5$ of the S6 length. 
A comparison of single mature females from tandems revealed several differences in $C$. mourae versus $C$. banditum: (a) pterostigma - dark brown vs reddish; (b) fossae - blackish, strongly contrasting vs brownish, not contrasting; (c) abdominal darkened rings at the end of S3-6 - present vs lacking; (d) dark longitudinal stripes on femora - distinct vs lacking. The traits seem to have diagnostic value as they are the same or very similar to those in males. In teneral females, darkened rings on S3-6 should be treated cautiously as they also occurred in a weaker form in a teneral (genetically confirmed) female of $C$. suave.

\section{Molecular analysis}

Among five males (Acc. MF947157-60, 62) and one female (Acc. MF947161) of C. mourae, sequenced for the COI barcoding fragment, we found only two haplotypes differing by one synonymous nucleotide substitution $(0.05 \% \mathrm{~K} 2 \mathrm{P})$. The final alignment for species delimitation comprised 657 nucleotide positions (nps) for 114 sequences representing 22 species of Ceriagrion including an outgroup (Supplemental Table S1). In the dataset, $419 \mathrm{nps}$ out of 657 were invariable (63.8\%), and transition to transversion ratio $(\mathrm{R})$ amounted to 1.7 . NJ analysis clustered the African COI sequences into well-supported clades corresponding to the known species, except $C$. glabrum and $C$. suave, which grouped in the same clade without any clear internal structure (Supplemental Figure S1). Excluding the C. glabrum/suave clade and outgroup, the mean genetic distance between $\mathrm{COI}$ sequence groups recovered in the $\mathrm{NJ}$ analysis was $12.32 \%(\mathrm{SD}=1.56)$ and ranged from $6.48 \%(\mathrm{SD}=0.92)$ between $C$. bakeri and $C$. junceum, to $18.46 \%$ ( $\mathrm{SD}=2.49$ ) between $C$. chaoi and C. obfuscans (Supplemental Table S2).

Ceriagrion mourae differed from its close relatives, $C$. bakeri by $7.01 \%$ ( $\mathrm{SD}=1.06), C$. junceum by $8.66 \%(\mathrm{SD}=1.24), C$. banditum by $9.03 \%(\mathrm{SD}=1.27)$, C. suave by $7.43 \%$ $(\mathrm{SD}=1.04)$ and $C$. glabrum by $7.17 \%(\mathrm{SD}=0.99)$; these values were sixfold to eightfold higher than the mean distance among $C$. glabrum/suave sequences $(1.13 \%, \mathrm{SD}=0.24)$. The

\section{Distance Value}

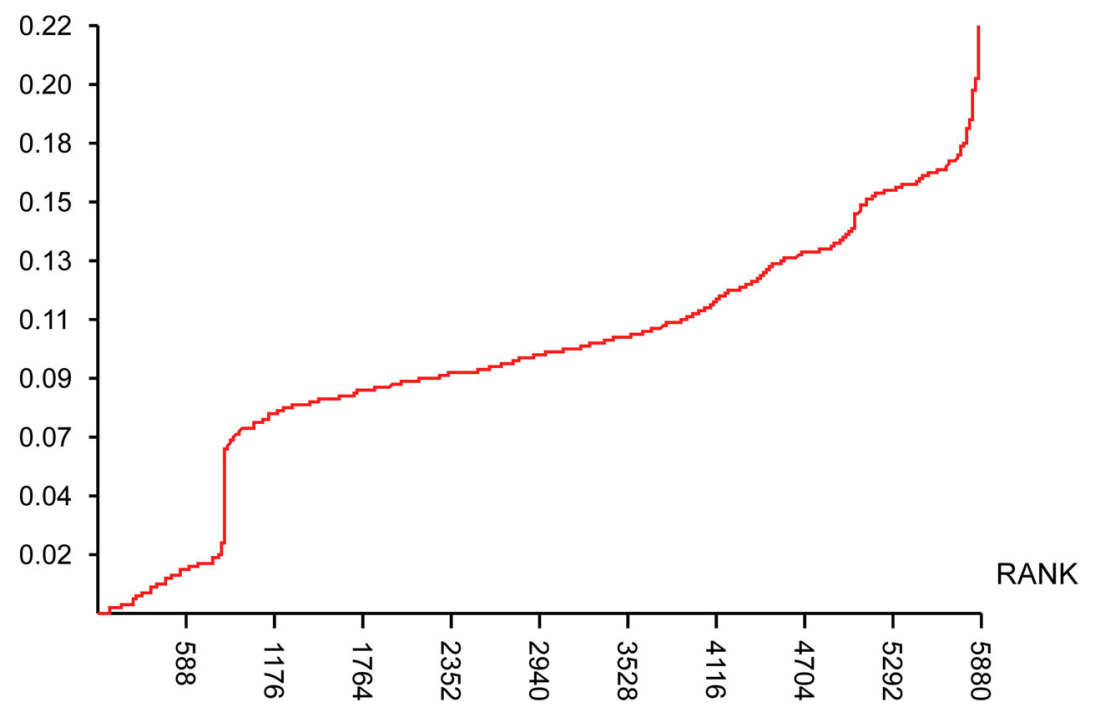

Figure 4. Barcode gap in the distribution of ranked pairwise differences found by the Automatic Barcode Gap Discovery (ABGD) for published COI sequences of Ceriagrion-species (results from http://wwwabi.snv.jussieu.fr/public/ abgd/abgdweb.html). 


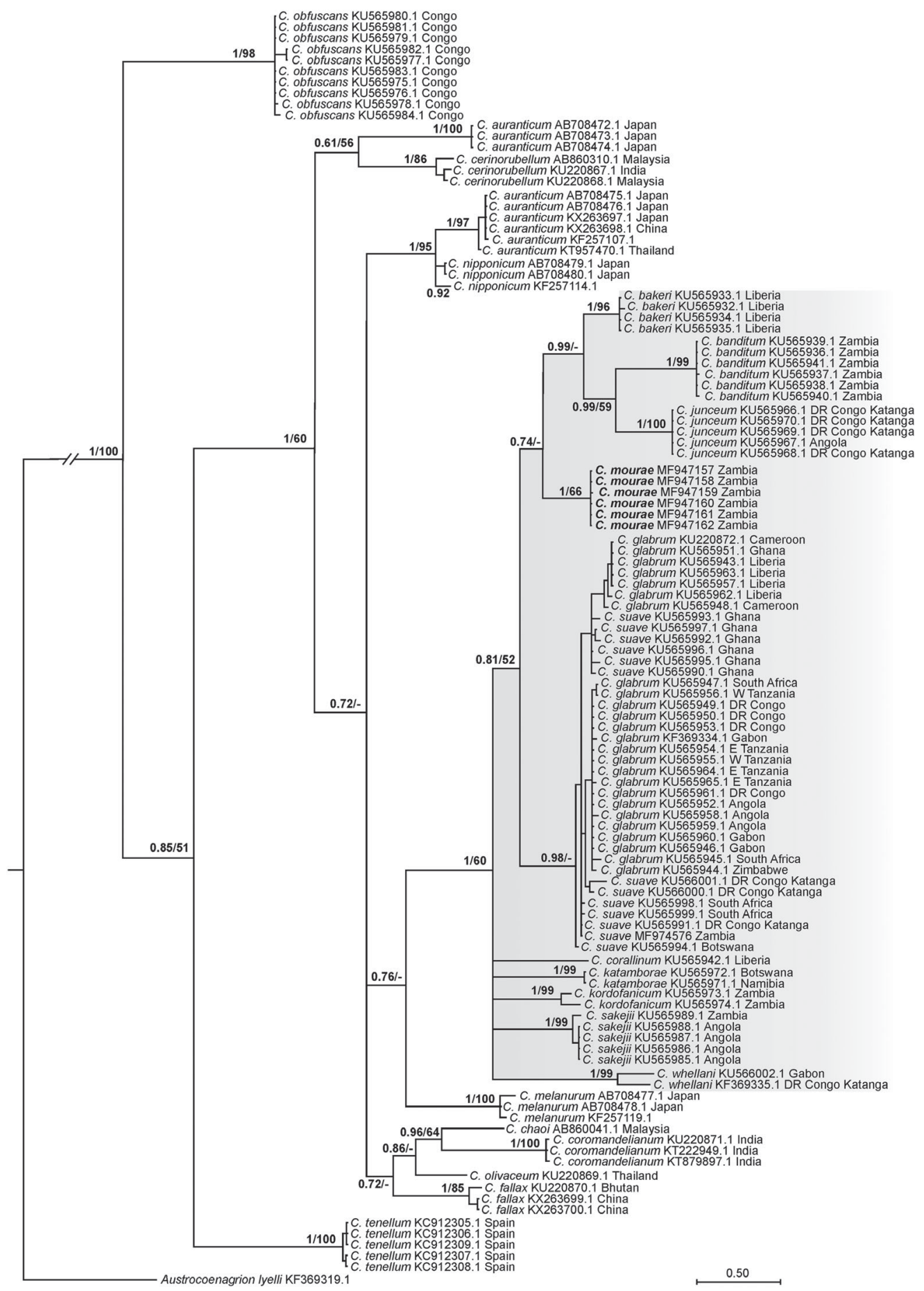

Figure 5. Bayesian (BI) tree based on the published COI sequences of Ceriagrion species. Values near branches show Bayesian posterior probability (PP) and bootstrap values (BS) in maximum likelihood tree (not shown); only supports $>0.50$ and 50\% are shown. Ceriagrion mourae is given in bold and the well-supported African clade, called glabrum-group by Dijkstra and Clausnitzer (2014), is shaded grey. 
ABGD analysis of all Ceriagrion COI sequences revealed a barcoding gap between 2 and $6.5 \%$ in the pairwise distance distribution (Figure 4) and grouped African sequences according to the known species, except for the otherwise morphologically distinct $C$. suave and C. glabrum.

Phylogenetic analysis based on BI and ML methods revealed that $C$. mourae is the sister taxon to the clade grouping $C$. bakeri, $C$. banditum and $C$. junceum; however, with weak support ( $\mathrm{PP}=0.74, \mathrm{BS}<50 \%$ ) (Figure 5). It also revealed the well-supported clade grouping $C$. banditum and $C$. junceum $(\mathrm{PP}=0.99, \mathrm{BS}=59 \%$ ) and lack of any differentiating structure in the C. glabrum/suave clade: the COI sequences originating from both species were scattered within the clade with mostly poor support, numerous polytomies and very short branches (Figure 5). Although all species of the morphologically distinct African glabrum-group of Ceriagrion (Dijkstra \& Clausnitzer, 2014), for which the barcode is published, were recovered

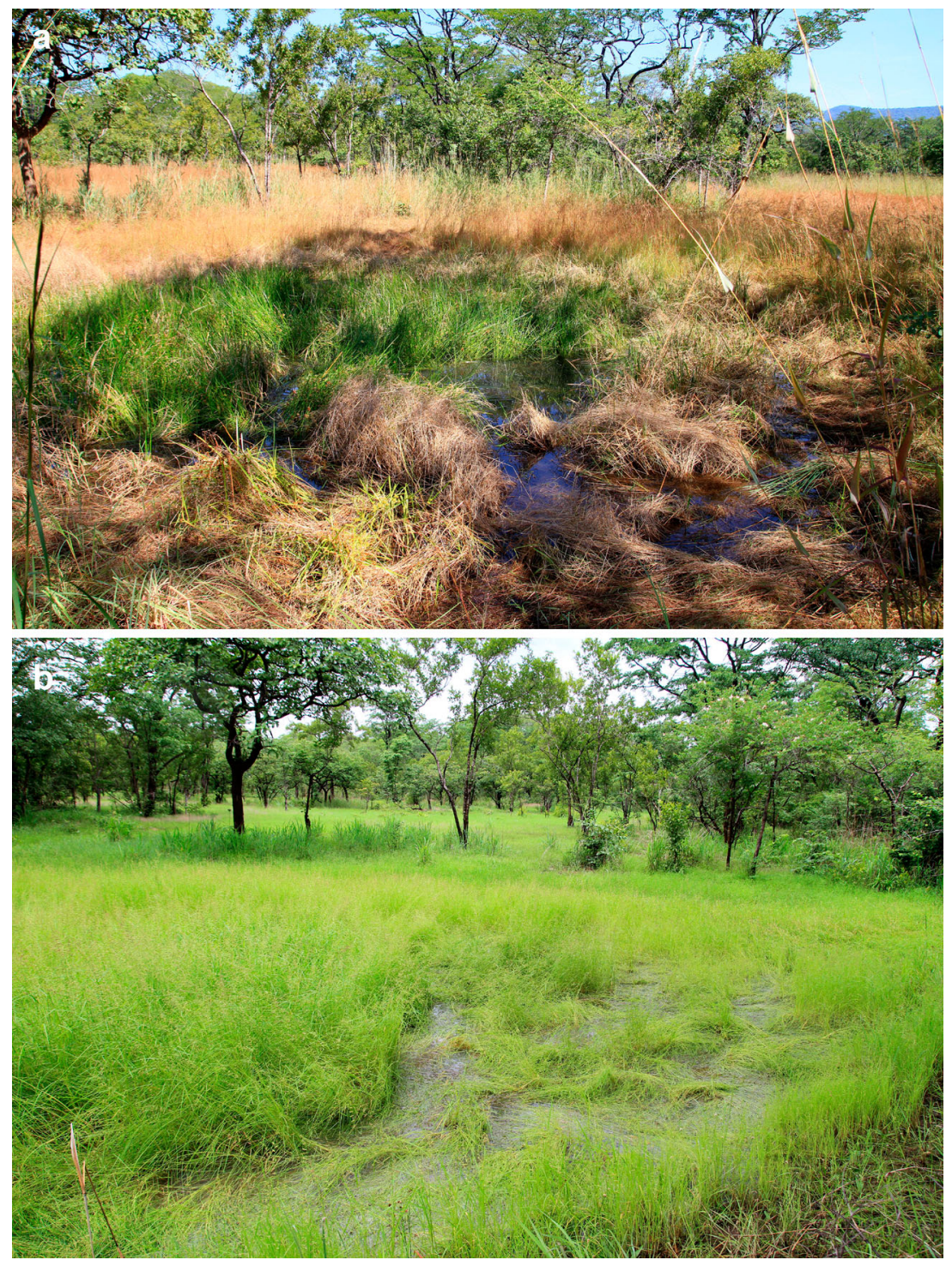

Figure 6. Habitat of C. mourae in Chingombe, Zambia: (a) before the drought of 2016, with predominating Schoenoplectiella lateriflora; (b) after the drought of 2016, with grasses only. 
in a well-supported ( $\mathrm{PP}=1, \mathrm{BS}=60 \%$ ) clade (shaded grey in Figure 5), most reciprocal phylogenetic relationships between the species were unresolved.

\section{Ecology and biology}

C. mourae was recorded in lightly wooded plains at the bottom of the rift valley, at a small pool situated on the upper reach of a narrow temporary stream. The pool was surrounded by mostly young miombo woodlands and open grassy areas.

Several dozens of other localities in broad environs of Chingombe were carefully but unsuccessfully searched for the species. They included both permanent and temporary waters, e.g. many other astatic pools and flooded areas. These localities were situated in surrounding plains, on adjacent slopes of the Muchinga Escarpment and on the upland plateau.

The inhabited pool differed by the combination of partial shading by an overhanging tree, the fairly dense presence of Schoenoplectiella lateriflora, and water depth exceeding $0.5 \mathrm{~m}$ in the rainy season (Figure 6a). In 2017, after severe drought in 2016, the dense vegetation was entirely grassy, with $S$. lateriflora absent (Figure 6b).

The emergence of $C$. mourae was recorded at the very end of the rainy season, between 20 and 23 April. On 26, 27 and 29 April no individuals of C. mourae were observed. The individuals were recorded only at the emergence pool and in an adjacent small patch of young miombo woodlands, but never in the adjacent open grassy areas. The emergence of $C$. suave occurred at the same time in the same pool, with teneral individuals recorded on the 21 and 27 April. A teneral male of $C$. banditum was also collected nearby, from another small pool on the same stream on 20 April. No adult Ceriagrion was observed there in April.

Adults of $C$. mourae were recorded in the peak of the rainy season, on 16-17 January, but were absent on 29 January. No other Ceriagrion species was recorded in January.

\section{Discussion}

\section{Morphology and taxonomy}

Some traits, e.g. shape of cerci in dorsal view and all appendages in caudal view, minutely toothed dorsal invagination of S10, brown colour of pterostigma and dorsal dark stripe on femora, are accurately presented in the original description of C. mourae (Pinhey, 1969). Some other traits are, however, slightly different in Zambian males: pterostigma is more oblique, slightly shorter and often slightly broadened distally, and the lower margin of paraprocts is obtusely angled rather than gently sloped. These differences are, however, only a result of some inaccuracy in the original description: in the received photographs of the holotype these traits look identical to those of Zambian males.

In the original description the species appears quite uniform, 'ochreous', locally with some additional tones, e.g. 'brownish ochreous'. In fact, the colour-spectrum is richer and colours are much more differentiated between the head, thorax and abdomen. For example, neither labium nor labrum are ochreous, but are yellow with different tones and intensity. A 'brownish ochreous abdomen with pinkish tinge on distal segments' appears, in fact, dull orange with a narrow red tone dorsally, and the difference between this and the ochreous thorax is striking. The distinctive abdominal rings and two-coloured eyes with 'bandit' rings are not mentioned by Pinhey (1969). These differences suggest that poorly preserved, already partly discoloured specimen might have been described.

Some traits specific for C. mourae were given accurately in the published keys (Dijkstra, 2005; Dijkstra \& Clausnitzer, 2014). The distinctiveness of the species could be more stressed in future 
keys with an addition of the structure of the cerci (not only their outline) and some colour/pattern features, especially abdominal rings and possibly also eye 'bandit' rings. The last trait, believed to be diagnostic for $C$. banditum (Dijkstra et al., 2015), also turned out to occur regularly in C. mourae. Another trait suggested as potentially distinguishing C. mourae, 10 rather than $12-$ 14 FwPx (Dijkstra et al., 2015), has turned out to be less diagnostic, as 10-12 (mostly 11) Px actually occur in Fw.

The molecular data support $C$. mourae as a distinct species. The phylogenetic tree suggests a sister relationship between $C$. mourae and the well supported clade $(C$. bakeri $(C$. banditum, C. junceum)). The occurrence of the latter clade has already been shown by Dijkstra et al. (2015); however, internal grouping of species into subclades was different, i.e. (C. banditum (C. bakeri, C. junceum)), and unsupported. Better supports for these relationships in our tree may result from the inclusion of $C$. mourae and rooting the tree by a species outside the genus (Figure 5).

\section{Remarks on zoogeography and ecology}

The new Zambian locality is situated $c .750 \mathrm{~km}$ north-west of Mamunge in Mozambique Plain and c. $1160 \mathrm{~km}$ south-west of Kichi in the Rufiji District in Tanzania (Figure 7). Considering the c. $1370 \mathrm{~km}$ between Mamunge and Kichi, the three known localities of $C$. mourae are scattered over large areas of eastern and southern central Africa. They are situated in plains and low hilly areas (Figure 7).

The temporal distribution of records of tenerals and adults in the Zambian habitat suggests reproductive activity in the first phase of the rainy season up to its peak and larval development during the rainy season followed by the emergence at its end.

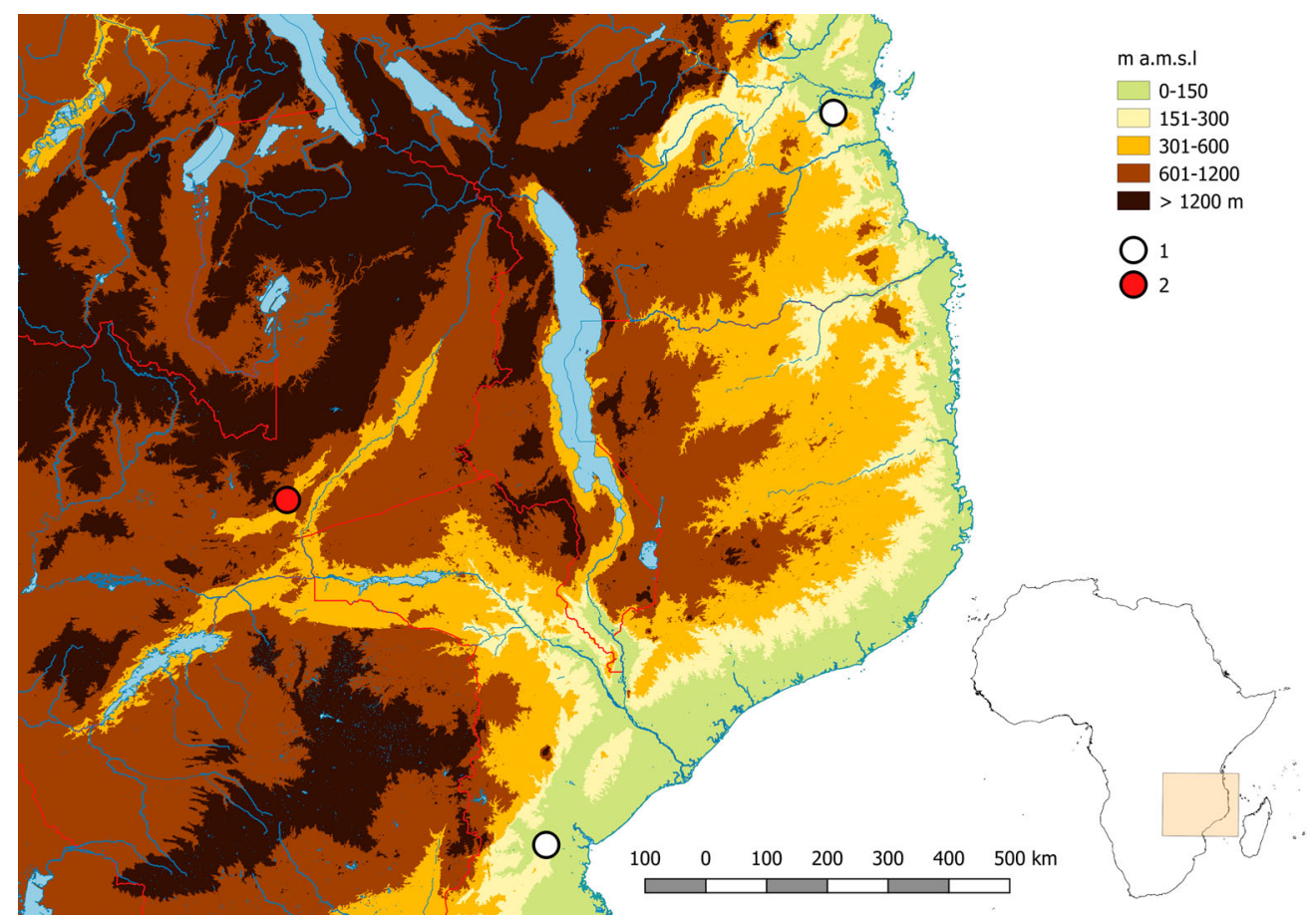

Figure 7. Situation of known localities of C. mourae on the background of altitude. 1 - published localities in Mozambique and Tanzania (Pinhey, 1969; Clausnitzer, 2006); 2 - a new locality in Zambia. 
The extremely restricted occurrence of $C$. mourae in the study area seems to follow its habitat requirements and rarity of favourable habitats there. The Zambian locality lies at a relatively low elevation in hot, open woodlands. In an area dominated by temporary waters, C. mourae inhabited only the most persistent one as reflected by the more water-dependent vegetation of Schoenoplectiella found nowhere else in the study area.

The habitat of $C$. mourae in Tanzania, i.e. a seasonal puddle in the miombo woodlands (Clausnitzer, 2006), looks quite similar as far as its size, water regime and woodland matrix are concerned. Accordingly, the presence of teneral individuals between 6 and 11 May (Clausnitzer, 2006) suggests a generally similar life cycle pattern as in Zambia.

\section{Acknowledgements}

We are grateful to K.-D.B. Dijkstra and J. Kipping for their valuable remarks, and to Kudzai Mafuwe from the Natural History Museum of Zimbabwe in Bulawayo for sending photographs of the holotype. These studies would be impossible without the warm hospitality and far-reaching help of the late unusually good man, Reverend Marceli Prawica from the Chingombe Mission.

\section{Supplemental data}

Supplemental data for this article can be accessed at https://doi.org/10.1080/13887890.2018.1464524

\section{References}

Clausnitzer, V. (2006). Dragonflies (Odonata) of Rufiji District, Tanzania with new records for Tanzania. Journal of East African Natural History, 95, 139-162. doi:10.2982/0012-8317(2006)95[139:DOORDT]2.0.CO;2

Dabert, M., Witalinski, W., Kazmierski, A., Olszanowski, Z., \& Dabert, J. (2010). Molecular phylogeny of acariform mites (Acari, Arachnida): Strong conflict between phylogenetic signal and long-branch attraction artifacts. Molecular Phylogenetics and Evolution, 56, 222-241. doi:10.1016/j.ympev.2009.12.020

Dijkstra, K.-D. B. (2005). A review of continental Afrotropical Ceriagrion (Odonata, Coenagrionidae). Journal of Afrotropical Zoology, 2, 3-14.

Dijkstra, K.-D. B., \& Clausnitzer, V. (2014). The dragonflies and damselflies of Eastern Africa: Handbook for all Odonata from Sudan to Zimbabwe. Studies in Afrotropical Zoology, vol. 298. Tervuren, Belgium: Royal Museum for Central Africa.

Dijkstra, K.-D. B., Boudot, J.-P., Clausnitzer, V., Kipping, J., Kisakye, J. J., Ogbogu, S. S., Samraoui, B., Samways, M. J., Schütte, K., Simaika, J. P., Suhling, F., \& Tchibozo, S. L. (2011). Dragonflies and damselflies of Africa (Odonata): history, diversity, distribution, and conservation. In W. R. T. Darwall, K. G. Smith, D. J. Allen, R. A. Holland, I. J. Harrison, \& E. G. E. Brooks (Eds.), The diversity of life in African freshwaters: under water, under threat: An analysis of the status and distribution of freshwater species throughout mainland Africa (pp. 128-177). Cambridge, UK and Gland, Switzerland: IUCN.

Dijkstra, K.-D. B., Kipping, J., \& Mézière, N. (2015). Sixty new dragonfly and damselfly species from Africa (Odonata). Odonatologica, 44, 447-678. doi:10.5281/zenodo.35388

Kimura, M. (1980). A simple method for estimating evolutionary rate of base substitutions through comparative studies of nucleotide sequences. Journal of Molecular Evolution, 16, 111-120.

Kumar, S., Stecher, G., \& Tamura, K. (2016). MEGA7: Molecular Evolutionary Genetics Analysis Version 7.0 for bigger datasets. Molecular Biology and Evolution, 33, 1870-1874. doi:10.1093/molbev/msw054

Lanfear, R., Calcott, B., Ho, S. Y. W., \& Guindon, S. (2012). PartitionFinder: Combined selection of partitioning schemes and substitution models for phylogenetic analyses. Molecular Biology and Evolution, 29, 1695-1701. doi:10.1093/molbev/mss020

Pinhey, E. (1969). Two new species of Zygoptera (Odonata). Novos Taxa Entomológicos, 66, 3-7.

Puillandre, N., Lambert, A., Brouillet, S., \& Achaz, G. (2012). ABGD, Automatic Barcode Gap Discovery for primary species delimitation. Molecular Ecology, 21, 1864-1877. doi:10.1111/j.1365-294X.2011.05239.x

Ronquist, F., Teslenko, M., van der Mark, P., Ayres, D. L., Darling, A., Höhna, S., Larget, B., Liu, L., Suchard, M. A., \& Huelsenbeck, J. P. (2012). MrBayes 3.2: efficient Bayesian phylogenetic inference and model choice across a large model space. Systematic Biology, 61, 539-542. doi:10.1093/sysbio/sys029

Zwickl, D. J. (2006). Genetic algorithm approaches for the phylogenetic analysis of large biological sequence datasets under the maximum likelihood criterion (PhD Thesis). The University of Texas, Austin. 